\title{
Beneficial effect of a polyphenol-rich diet on cardiovascular risk: a randomised control trial
}

\author{
Rebecca L Noad ${ }^{1,2}$ Ciara Rooney, ${ }^{1}$ Damian McCall, ${ }^{2}$ Ian S Young, ${ }^{1,2}$ \\ David McCance, ${ }^{2}$ Michelle C McKinley, ${ }^{1,3}$ Jayne $V$ Woodside, ${ }^{1,3}$ Pascal P McKeown ${ }^{1,2}$
}

- Additional material is published online only. To view please visit the journal online (http://dx.doi.org/10.1136/ heartjnl-2015-309218).

${ }^{1}$ Centre for Public Health, Queen's University Belfast, Belfast, UK

${ }^{2}$ Cardiology Department, Belfast Health and Social Care Trust, Belfast, UK

${ }^{3}$ UKCRC Centre of Excellence for Public Health, Queen's University Belfast, Belfast, UK

\section{Correspondence to} Dr Rebecca L Noad, Centre for Public Health, Institute of Clinical Sciences B, Grosvenor Road, Belfast BT12 6BJ, UK; rnoad01@qub.ac.uk

Received 21 December 2015 Revised 10 April 2016 Accepted 11 April 2016 Published Online First 10 May 2016

\section{SLinked}

- http://dx.doi.org/10.1136/ heartinl-2016-309647

\section{CrossMark}

\author{
To cite: Noad RL, \\ Rooney C, McCall D, et al. \\ Heart 2016;102 \\ 1371-1379.
}

\section{ABSTRACT}

Objectives There is previous epidemiological evidence that intake of polyphenol-rich foods has been associated with reduced cardiovascular disease risk. We aimed to investigate the effect of increasing dietary polyphenol intake on microvascular function in hypertensive participants.

Methods All participants completed a 4-week run-in phase, consuming $<2$ portions of fruit and vegetables (F\&V) daily and avoiding berries and dark chocolate. Subjects were then randomised to continue with the low-polyphenol diet for 8 weeks or to consume a highpolyphenol diet of six portions F\&V (including one portion of berries/day and $50 \mathrm{~g}$ of dark chocolate). Endothelium-dependent (acetylcholine, ACh) and endothelium-independent (sodium nitroprusside) vasodilator responses were assessed by venous occlusion plethysmography. Compliance with the intervention was measured using food diaries and biochemical markers. Results Final analysis of the primary endpoint was conducted on 92 participants. Between-group comparison of change in maximum \% response to ACh revealed a significant improvement in the highpolyphenol group $(p=0.02)$. There was a significantly larger increase in vitamin C, carotenoids and epicatechin in the high-polyphenol group (between-group difference $p<0.001 ; p<0.001 ; p=0.008$, respectively).

Conclusions This study has shown that increasing the polyphenol content of the diet via consumption of $F \& V$, berries and dark chocolate results in a significant improvement in an established marker of cardiovascular risk in hypertensive participants.

Trial registration number NCT01319786.

Previous epidemiological and intervention study evidence suggests that increasing fruit and vegetable (F\&V) consumption improves cardiovascular disease (CVD) risk. ${ }^{1}$ A previous dietary intervention by McCall and colleagues in hypertensive subjects (Fruit and Vegetable Randomised Intervention Trial, FAVRIT) demonstrated a $6 \%$ improvement in endothelium-dependent vasodilation, as a measure of vascular function, for every portion/day increase in fruit or vegetables. ${ }^{2}$ Post hoc analysis of the FAVRIT data indicated that berry consumption was the class of fruit most associated with an improvement in microvascular function. It was hypothesised that this could be attributed to berries with high polyphenol content. Observational evidence to date indicates that polyphenol-rich foods, in particular berries ${ }^{3} 4$ and dark chocolate, ${ }^{5-7}$ may influence CVD risk. However, there are few polyphenol-specific dietary intervention studies of sufficiently robust design that assess the effect of polyphenol-rich foods on microvascular function.

The aim of the Polyphenol Intervention Trial (PPhIT) was to investigate if increasing overall polyphenol dietary intake (through the consumption of six portions of $\mathrm{F} \& \mathrm{~V} /$ day including one portion of berries and $50 \mathrm{~g}$ of dark chocolate) would affect microvascular function, measured by forearm blood flow (FBF) responses to an endotheliumdependent vasodilator, and also have a beneficial effect on a range of other markers of CVD risk, such as systolic blood pressure (SBP) and lipid profile, in patients with hypertension.

The FBF measure of microvascular function was chosen as the primary endpoint, due to its use in previous dietary interventions, including the FAVRIT study, ${ }^{2}$ and because responses to endotheliumdependent vasodilators such as acetylcholine (ACh) have previously been shown to be reduced in individuals with hypertension. ${ }^{8} 9 \mathrm{FBF}$ responses to $\mathrm{ACh}$ have also been independently associated with cardiovascular morbidity in hypertensive patients ${ }^{10}$ and, in those with established CVD, improved FBF responses were significantly correlated with improved survival after acute coronary syndrome. ${ }^{11}$

Participants with hypertension were chosen because they represent a common cardiovascular risk cohort in whom modification of diet is feasible. There are several studies linking hypertension with reduced response to endothelium-dependent vasodilators. $^{8} \quad 9{ }^{12}$ In addition, the current European Society of Cardiology guidelines for management of hypertension endorse increasing $\mathrm{F} \& \mathrm{~V}$ intake to five portions per day, based on studies of a Mediterranean diet, ${ }^{13}$ making it a relevant population in which to conduct a randomised controlled dietary intervention trial. ${ }^{14}$

\section{METHODS}

\section{Overview of study and endpoints}

The study used a 12-week randomised controlled, single-blinded dietary intervention design. The study commenced with a four-week 'run-in phase' for all participants, during which they were asked to consume two portions or less of $F \& V$, and to exclude berries and dark chocolate (low-polyphenol diet). At the end of this period, subjects were randomised to continue with the above low-polyphenol diet for a further 8-week 'intervention period' or to consume a high-polyphenol diet of six portions $\mathrm{F} \& \mathrm{~V}$ (including one portion of berries per day) and $50 \mathrm{~g}$ of dark chocolate per day (figure 1). 


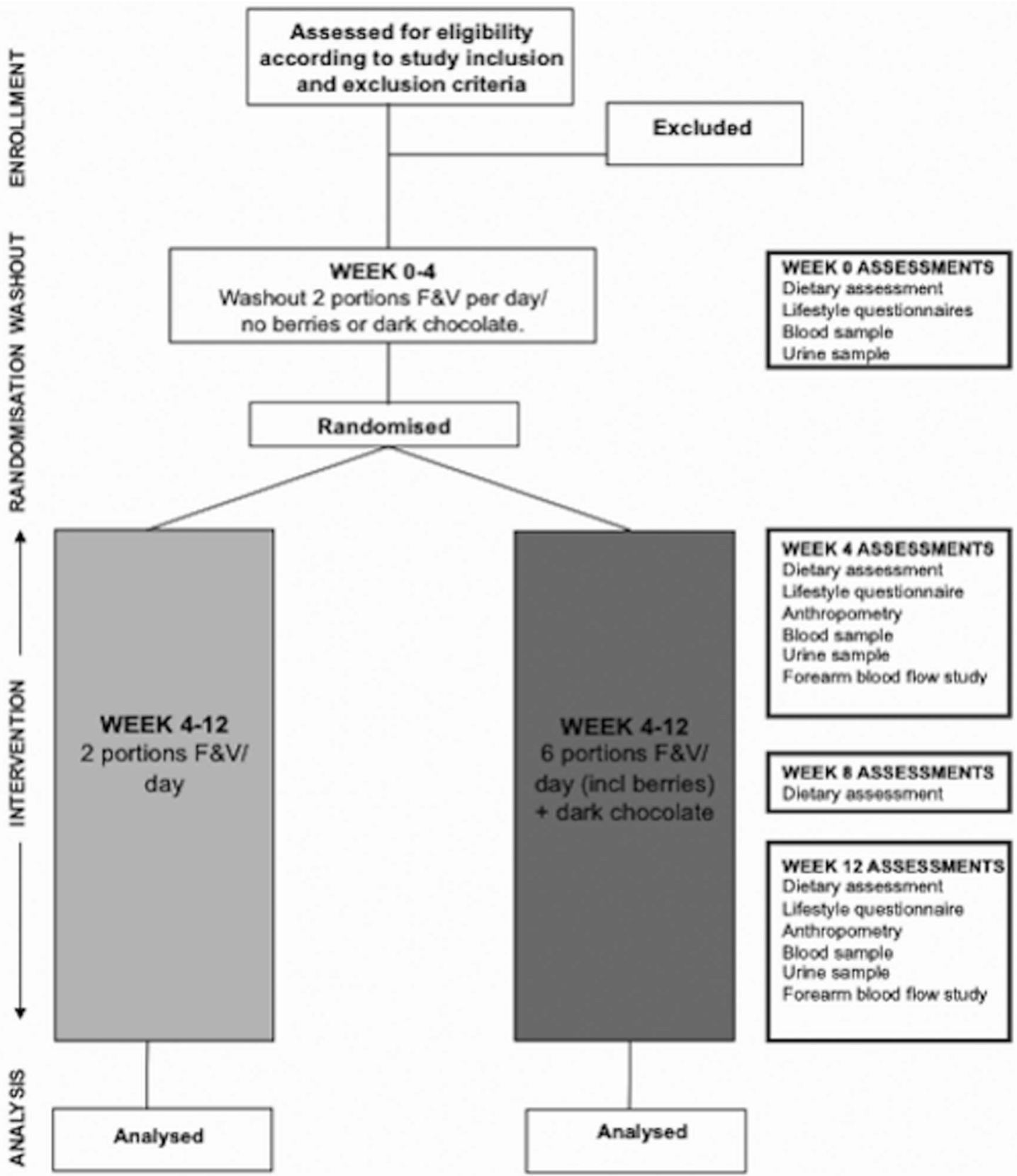

Figure 1 Overview of study design. F\&V, fruit and vegetables.

The primary endpoint was between-group change in maximum FBF response to the endothelium-dependent vasodilator, ACh. Secondary endpoints included between-group change in self-reported polyphenol-rich food intake, between-group change in biochemical markers of nutritional status and between-group change in SBP and lipid profile. The study had ethical approval from the Office of Research Ethics Committee Northern Ireland (ref 10/NIR03/39) and was registered at ClinicalTrials.gov (ref NCT01319786).

\section{Inclusion criteria}

Participants aged 40-65 years, with documented grade I (140$159 / 90-99 \mathrm{~mm} \mathrm{Hg})$ or grade II (160-179/100-109 mm Hg) hypertension, were eligible. ${ }^{15}$ Potential participants had brachial blood pressure (BP) measured after 10 min rest using an Omron M5-1 automatic BP monitor (Omron Healthcare, Hoofdorp, Netherlands) from the dominant arm. Three consecutive measurements were recorded and a summary BP calculated from the second and third readings.

\section{Exclusion criteria}

Exclusion criteria included diabetes mellitus, acute coronary syndrome or transient ischaemic attack within 3 months, pregnancy or lactation, fasting triglyceride concentration $>4 \mathrm{mmol} /$ L, alcohol consumption ( $>28$ units/week for men and $>21$ units/week for women), oral anticoagulant therapy or antioxidant supplements, dietary restrictions that would limit ability to comply with the study diets and body mass index (BMI) $>35 \mathrm{~kg} / \mathrm{m}^{2}$ with an impalpable brachial artery.

\section{Randomisation}

Participants' baseline habitual polyphenol dietary content was measured at the screening visit using a modified version of the food frequency questionnaire developed for the European 
Prospective Investigation of Cancer study. ${ }^{16}$ Eligible participants were stratified into high-polyphenol or low-polyphenol consumers and then block randomised using a random-number generator (http://www.randomization.com, block size $n=6$ ). The investigator performing FBF assessment (RLN) and staff conducting laboratory analysis were blinded to diet allocation.

\section{Dietary intervention}

Participants received individual nutrition consultations with a nutrition researcher (CR), as well as literature regarding portion sizes based on the UK Food Standard Agency guidelines (http:// www.eatwell.gov.uk). All participants in the high-polyphenol diet had a self-selected weekly delivery of F\&V and dark chocolate (Lindt 70\% cocoa) free of charge to their homes from a local supermarket. Each participant was also contacted by telephone at weekly intervals. At each study visit, weight, hip and waist circumference were measured and questionnaires completed to quantify any change in level of physical activity.

\section{Measurement of compliance}

Dietary compliance was assessed using four-day food diaries on four occasions, two unannounced 24 -h recalls and daily study food records completed by participants. Biochemical assessment of nutritional status included measurement of plasma vitamin $\mathrm{C}$ and carotenoids. To specifically monitor for dark chocolate consumption, urinary epicatechins were measured, as these represent one of the major polyphenols in cocoa. ${ }^{17}$

\section{Assessment of vascular function}

Participants attended for assessments of microvascular function before and after the 8 -week intervention period. Room temperature was maintained at $22^{\circ} \mathrm{C}-24^{\circ} \mathrm{C}$. All testing was performed by a single investigator (RLN) who remained blinded to intervention phase dietary allocations throughout the study and during statistical analysis. Participants attended between 07:00 and 11:00 h, having fasted for at least $12 \mathrm{~h}$ and refrained from ingestion of caffeine, alcohol, nicotine or long-acting nitrate preparations.

Venous occlusion plethysmography was used to determine FBF during intra-arterial infusions of $\mathrm{ACh}$ and sodium nitroprusside (SNP), endothelium-dependent and endotheliumindependent vasodilators, respectively. Each FBF study was conducted according to an established standard operating procedure within the facility. ${ }^{2}$ After infiltration with $1 \%$ lidocaine, a

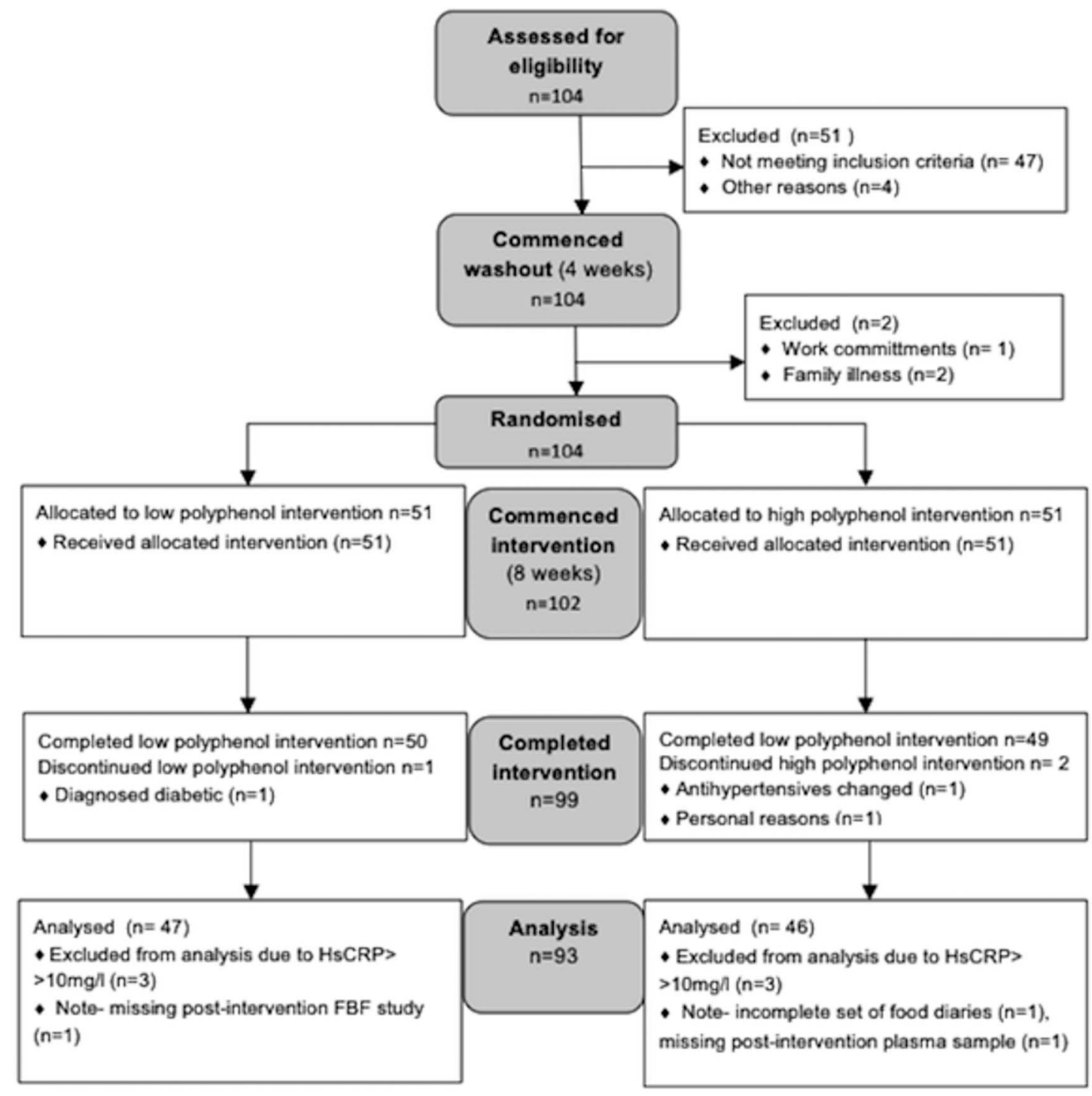

Figure 2 CONSORT flow diagram summarising patient recruitment. FBF, forearm blood flow; hsCRP, highly sensitive C-reactive protein. 
27-gauge sterile needle (Cooper's Needle Works, Birmingham, UK) was inserted into the non-dominant brachial artery using an aseptic technique. At baseline and during vasodilator administration, plethysmographic measurements were made with electrically calibrated mercury-in-silastic strain gauges (PMS Instruments, Maidenhead, UK) in both the infused and noninfused limbs, to control for unexpected stimuli. ${ }^{18}$ Each strain gauge was attached to a Hokanson EC6 plethysmograph (PMS Instruments), which in turn was connected to a dedicated computer on which the Hokanson NIVP3 Dual Channel software (V.5.40, PMS Instruments) was installed. Initially saline was infused through the needle via an epidural catheter at a rate of $1 \mathrm{~mL} / \mathrm{min}$ for at least $30 \mathrm{~min}$, followed by incremental intra-arterial infusions of ACh (50, 100 and $200 \mathrm{nmol} / \mathrm{min})$ and SNP $(5,10$ and $20 \mathrm{nmol} / \mathrm{min})$. Each concentration was infused for 5 min before five FBF readings were made during $7 \mathrm{~s}$ periods of venous occlusion separated by $20 \mathrm{~s}$ intervals.

Mean inflow curve gradients for each concentration of both infusions were calculated using NIVP3 software. This was performed for infused and control arms to yield flow rates in $\mathrm{mL} /$ $100 \mathrm{~mL}$ forearm volume (ie, \% change). Each participant's responses were summarised by curves of $\%$ increase in infused: non-infused ratio against vasodilator dose. The summary measure used was maximum vasodilator response observed. ${ }^{10}$

\section{Laboratory analysis}

Plasma vitamin C was measured on a FLUOstar Optima plate reader (BMG Labtech, Ortenberg, Germany) adapted from the method by Vuilleumier and Keck. ${ }^{19}$ Serum concentrations of six carotenoids ( $\alpha$-carotene, $\beta$-carotene, $\beta$-cryptoxanthin, lutein, lycopene and zeaxanthin) were measured by reverse-phase highperformance liquid chromatography (HPLC) as described by Craft. $^{20}$ Fasting serum lipid profiles (total cholesterol, high-density lipoprotein and triglycerides) were assessed using standard enzymatic colorimetric assays on an automated Cobas 8000 Modular system biochemical analyser (Roche Diagnostics, West Sussex, UK).
Low-density lipoprotein (LDL) cholesterol was calculated using a standard Friedewald formula. ${ }^{21}$ Urine collected from the volunteers between evening meal and midnight the day before each study visit was analysed, including an enzymatic hydrolysis step, to quantify total epicatechin content using an Agilent Technologies 1100 series HPLC (Agilent Technologies, Stockport, UK) directly linked to a Waters Micromass Quattro Ultima Platinum API triple quadrupole mass spectrometer (Waters, Dublin, Ireland).

\section{Statistical analysis and power calculation}

Results are expressed as mean \pm SD for normally distributed continuous variables. Skewed variables were log-transformed and summarised as geometric mean and IQR, where appropriate. The principal analysis for each outcome variable was a between-group comparison of change using independent sample $\mathrm{t}$ tests or $\chi^{2}$ test. These analyses were confirmed using analysis of covariance using postintervention values as the outcome variable and adjusting for preintervention values. Within-group comparisons were performed using paired samples $t$ tests. Univariate linear regression analysis was also used to further examine vascular function results. All statistical analyses were performed using SPSS V.20 (SPSS, Chicago, Illinois, USA).

The power calculation was based on data collected as part of the FAVRIT study. ${ }^{2}$ To detect a 33\% difference (the difference detected in FAVRIT) between groups in this variable with $90 \%$ power using a two-tailed test at the 5\% significance level would require 50 participants per group. Participants who were found to have an elevated highly sensitive C-reactive protein (hsCRP) $>10 \mathrm{mg} / \mathrm{L}$ at any point in the study, indicating acute inflammation, were excluded from final analysis, in line with American Heart Association guidelines. ${ }^{22}$

\section{RESULTS}

\section{Summary of recruitment}

The CONSORT recruitment summary is illustrated in figure 2. Overall, 155 individuals attended for screening. Of these, 51

Table 1 Pre-eight-week intervention period participant characteristics according to diet allocation

\begin{tabular}{|c|c|c|c|}
\hline & $\begin{array}{l}\text { Low polyphenol } \\
(n=47)\end{array}$ & $\begin{array}{l}\text { High polyphenol } \\
(n=46)\end{array}$ & $\begin{array}{l}\text { Between-group comparison } \\
\text { p value }\end{array}$ \\
\hline Age (years)* & $55.6(6.8)$ & $54.0(6.7)$ & 0.235 \\
\hline Male $(\%) \dagger$ & $28(59.6)$ & $22(47.8)$ & 0.301 \\
\hline Body mass index $\left(\mathrm{kg} / \mathrm{m}^{2}\right)^{*}$ & $29.8(5.0)$ & $31.6(6.5)$ & 0.148 \\
\hline Systolic blood pressure $(\mathrm{mm} \mathrm{Hg})^{*}$ & $141.7(9.3)$ & $140.6(8.9)$ & 0.589 \\
\hline Diastolic blood pressure $(\mathrm{mm} \mathrm{Hg})^{*}$ & $85.5(6.9)$ & $84.5(7.6)$ & 0.460 \\
\hline Current smoker (\%)† & $4(8.5)$ & $6(13.0)$ & 0.523 \\
\hline Former smoker (\%)† & $24(51.1)$ & $18(39.1)$ & 0.300 \\
\hline Antihypertensive therapy (\%)† & $37(78.7)$ & $36(78.3)$ & 0.999 \\
\hline Lipid-lowering therapy (\%)† & $21(44.7)$ & $19(41.3)$ & 0.835 \\
\hline Total cholesterol $(\mathrm{mmol} / \mathrm{L})^{*}$ & $5.2(1.2)$ & $5.8(1.3)$ & 0.020 \\
\hline $\mathrm{HDL}(\mathrm{mmol} / \mathrm{L})^{*}$ & $1.4(0.4)$ & $1.4(0.4)$ & 0.568 \\
\hline $\mathrm{LDL}(\mathrm{mmol} / \mathrm{L})^{*}$ & $4.2(1.3)$ & $4.7(1.4)$ & 0.038 \\
\hline Triglycerides (mmol/L) $\ddagger$ & $1.6(1.0,2.3)$ & $1.6(1.1,2.1)$ & 0.796 \\
\hline Total cholesterol/HDL ratio* & $3.9(1.3)$ & $4.2(1.2)$ & 0.267 \\
\hline Max response ACh (infused:non-infused) $(\%)^{*} \S$ & $123.9(99.6)$ & $109.1(84.7)$ & 0.447 \\
\hline $\begin{array}{l}\text { Max response SNP } \\
\text { (infused:non-infused) }(\%)^{*} \S\end{array}$ & $126.3(120.4)$ & $107.7(70.1)$ & 0.369 \\
\hline \multicolumn{4}{|c|}{$\begin{array}{l}\text { Bold figures signify significant } p \text { values. } \\
\text { *Normally distributed data summarised as mean (SD). Difference between groups assessed using independent samples } t \text { test. } \\
\text { tCategorical variables are summarised as } n(\%) \text {. Difference between groups assessed using } \chi^{2} \text { test. } \\
\text { ‡Skewed data were logarithmically transformed and presented as geometric mean (IQR). Difference between groups assessed using independent samples } t \text { test. } \\
\text { \$Based on } 92 \text { subjects due to missing data for one participant in low-polyphenol group. } \\
\text { ACh, acetylcholine; HDL, high-density lipoprotein; LDL, low-density lipoprotein; SNP, sodium nitroprusside. }\end{array}$} \\
\hline
\end{tabular}


Table 2 Preintervention and postintervention period results of self-reported dietary intake and micronutrient concentrations by diet allocation

\begin{tabular}{|c|c|c|c|c|c|c|c|c|c|}
\hline & \multicolumn{2}{|l|}{$\begin{array}{l}\text { Low polyphenol } \\
(\mathrm{n}=47)\end{array}$} & \multirow[b]{2}{*}{ Change } & \multirow{2}{*}{$\begin{array}{l}\text { Within-group } \\
\text { p value }\end{array}$} & \multicolumn{2}{|l|}{$\begin{array}{l}\text { High polyphenol } \\
(n=46)\end{array}$} & \multirow[b]{2}{*}{ Change } & \multirow{2}{*}{$\begin{array}{l}\text { Within-group } \\
\text { p value }\end{array}$} & \multirow{2}{*}{$\begin{array}{l}\text { Between-group } \\
\text { p value }\end{array}$} \\
\hline & Pre & Post & & & Pre & Post & & & \\
\hline $\begin{array}{l}\text { F\&V intake }{ }^{*} \dagger \\
\text { (portions/day) }\end{array}$ & $1.38(0.80)$ & $1.25(0.57)$ & $-0.13(-0.35$ to 0.10$)$ & 0.252 & $1.40(0.71)$ & $6.82(2.12)$ & $5.42(4.71$ to 6.14$)$ & $<0.001$ & $<0.001$ \\
\hline $\begin{array}{l}\text { Berries (portions/ } \\
\text { day) }+\ddagger\end{array}$ & 0 & 0 & 0 & $N / A$ & 0 & 1.00 (0.80 to 1.25$)$ & 1.00 (0.77 to 1.25$)$ & $<0.001$ & $<0.001$ \\
\hline $\begin{array}{l}\text { Dark chocolate } \\
\text { (g/day) } \neq\end{array}$ & 0 & 0 & 0 & N/A & 0 & 50.0 (37.5 to 50.0$)$ & 50.0 (37.5 to 50.0$)$ & $<0.001$ & $<0.001$ \\
\hline $\begin{array}{l}\text { Epicatechin } \\
(\mathrm{nmol} / \mathrm{mol} \mathrm{crt})^{*}\end{array}$ & $0.12(0.20)$ & $0.10(0.12)$ & $-0.02(-0.08$ to 0.06$)$ & 0.629 & $0.10(0.30)$ & $0.30(0.29)$ & 0.19 (0.07 to 0.31$)$ & 0.002 & $<0.001$ \\
\hline $\begin{array}{l}\text { Vitamin C } \\
(\mu \mathrm{mol} / L)+\S\end{array}$ & 25.1 (18.3 to 52.3$)$ & 19.6 (11.8 to 48.9$)$ & 0.79 (0.63 to 0.96$)$ & 0.021 & 28.4 (18.6 to 57.5$)$ & 51.7 (43.9 to 68.6$)$ & 1.82 (1.34 to 7.25$)$ & $<0.001$ & $<0.001$ \\
\hline Lutein $(\mu \mathrm{mol} / \mathrm{L}) \S$ & $0.16(0.12$ to 0.20$)$ & $0.15(0.11$ to 0.20$)$ & $0.98(0.90$ to 1.06$)$ & 0.595 & $0.15(0.11$ to 0.19$)$ & $0.20(0.15$ to 0.26$)$ & 1.32 (1.22 to 1.44$)$ & $<0.001$ & $<0.001$ \\
\hline $\begin{array}{l}\text { Zeaxanthin } \\
(\mu \mathrm{mol} / \mathrm{L}) \S\end{array}$ & $0.04(0.03$ to 0.05$)$ & 0.04 (0.03 to 0.05$)$ & 0.97 (0.91 to 1.03$)$ & 0.331 & 0.04 (0.03 to 0.05$)$ & 0.05 (0.04 to 0.06$)$ & 1.18 (1.07 to 1.30$)$ & 0.001 & 0.001 \\
\hline $\begin{array}{l}\beta \text {-Cryptoxanthin } \\
(\mu \mathrm{mol} / L) \S\end{array}$ & 0.05 (0.04 to 0.08$)$ & 0.05 (0.03 to 0.08$)$ & $0.92(0.83$ to 1.03$)$ & 0.134 & 0.05 (0.04 to 0.07$)$ & $0.07(0.05$ to 0.10$)$ & $1.29(1.15$ to 1.45$)$ & $<0.001$ & $<0.001$ \\
\hline $\begin{array}{l}\alpha \text {-Carotene } \\
(\mu \mathrm{mol} / \mathrm{L}) \S\end{array}$ & 0.12 (0.09 to 0.16$)$ & $0.11(0.08$ to 0.14$)$ & 0.90 (0.82 to 0.99$)$ & 0.037 & $0.12(0.10$ to 0.15$)$ & 0.14 (0.11 to 0.20$)$ & 1.17 (1.05 to 1.30$)$ & 0.006 & 0.001 \\
\hline $\begin{array}{l}\beta \text {-Carotene } \\
(\mu \mathrm{mol} / /) \S\end{array}$ & $0.24(0.15$ to 0.36$)$ & 0.21 (0.14 to 0.32$)$ & $0.91(0.82$ to 1.01$)$ & 0.064 & $0.26(0.19$ to 0.36$)$ & $0.30(0.23$ to 0.42$)$ & $1.16(1.05$ to 1.28$)$ & 0.006 & 0.001 \\
\hline $\begin{array}{l}\text { Lycopene } \\
(\mu \mathrm{mol} / \mathrm{L}) \S\end{array}$ & 0.45 (0.33 to 0.69$)$ & 0.43 (0.33 to 0.58$)$ & 0.95 (0.85 to 1.06$)$ & 0.343 & $0.47(0.38$ to 0.66$)$ & 0.53 (0.41 to 0.69$)$ & $1.12(0.95$ to 1.31$)$ & 0.177 & 0.098 \\
\hline $\begin{array}{l}\text { Total carotenoids } \\
(\mu \mathrm{mol} / \mathrm{L}) \S\end{array}$ & 1.09 (0.84 to 1.47$)$ & 0.99 (0.75 to 1.34$)$ & $0.93(0.86$ to 1.09$)$ & 0.800 & 1.13 (0.91 to 1.36$)$ & 1.32 (1.06 to 1.67$)$ & 1.17 (1.06 to 1.29$)$ & 0.003 & 0.001 \\
\hline \multicolumn{10}{|c|}{ 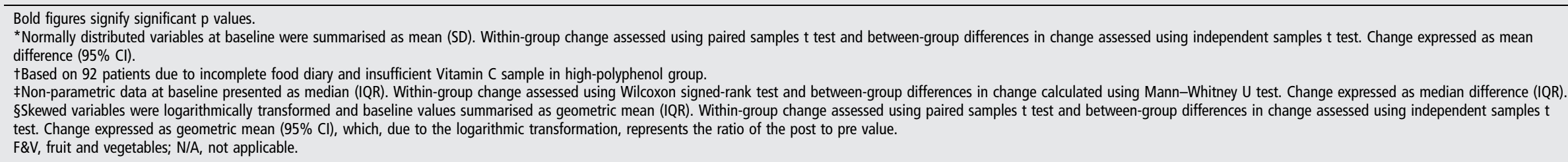 } \\
\hline
\end{tabular}


(33\%) did not meet the inclusion criteria or were unable to participate. In total, 104 participants commenced the study; two withdrew during the washout period due to family or work reasons. At randomisation, 102 patients (51 per group) were allocated to either a high-polyphenol or low-polyphenol diet. There were three dropouts during the intervention phase: two from the high-polyphenol group due to personal reasons and a change in antihypertensive therapy, respectively, and one from the low-polyphenol group due to personal illness. Therefore, 99 participants completed the study between January 2010 and April 2013.

Of these, six had a recorded serum hsCRP $>10 \mathrm{mg} / \mathrm{L}$ at one or more time points during the study and were excluded from further analyses. Of the remaining 93 participants, there were missing postintervention plasma samples required for vitamin $\mathrm{C}$ analysis for one participant, one patient did not return a complete set of food diaries, and postintervention FBF studies had to be abandoned in another patient due to computer hardware issues on that visit. A full data set was therefore available on a total of 90 participants. Baseline results prior to entry to washout period are not shown.

\section{Baseline characteristics}

Baseline preintervention characteristics recorded after the 4-week run-in period are summarised in table 1 . There were no significant differences between the two groups, with the exception of total cholesterol and LDL, which were both higher in the highpolyphenol group $(\mathrm{p}=0.020$ and $\mathrm{p}=0.038$, respectively).

\section{Changes in measure of compliance}

Results for self-reported polyphenol intake and micronutrients are summarised in table 2 . Between-group change showed a significant increase in self-reported polyphenol intake in the highpolyphenol group compared with the low-polyphenol group $(p<0.001$ for all). There was also a significant between-group difference in change in micronutrient status: concentrations of urinary epicatechin $(p<0.001)$, plasma vitamin $C(p<0.001)$ and all serum carotenoids (with the exception of lycopene $(p=0.098))$ with a significantly larger increase in the highpolyphenol group compared with the low-polyphenol group.

\section{Changes in microvascular function}

Comparison between the two dietary groups showed maximum $\%$ response to $\mathrm{ACh}$ (infused:non-infused arm ratios) was significantly improved in the high-polyphenol group $(p=0.02)$ relative to the control group (table 3 ). There was no significant difference in the between-group change in response to SNP $(p=0.17)$. Dose-response curves were plotted for mean saline and infused:non-infused ratios for each ACh concentration per group preintervention and postintervention (figure 3) to illustrate the improvement in high-polyphenol FBF postintervention. Further analysis of microvascular function is included in online supplementary appendix 1.

\section{Changes in markers of cardiovascular risk}

There were no significant changes in BMI within (lowpolyphenol group $29.8 \mathrm{~kg} / \mathrm{m}^{2}$ preintervention and $29.8 \mathrm{~kg} / \mathrm{m}^{2}$ postintervention $(\mathrm{p}=0.842)$, high-polyphenol group $31.6 \mathrm{~kg} / \mathrm{m}^{2}$ and $31.6 \mathrm{~kg} / \mathrm{m}^{2}$ post $\left.(\mathrm{p}=0.961)\right)$ or between groups $(\mathrm{p}=0.897)$ during the intervention (table 3 ). There was a trend towards a larger decrease in SBP in the high-polyphenol group compared with the low-polyphenol group; this was of borderline statistical significance $(p=0.059)$. Within-group analysis found that SBP decreased significantly within both the low-polyphenol (141.7

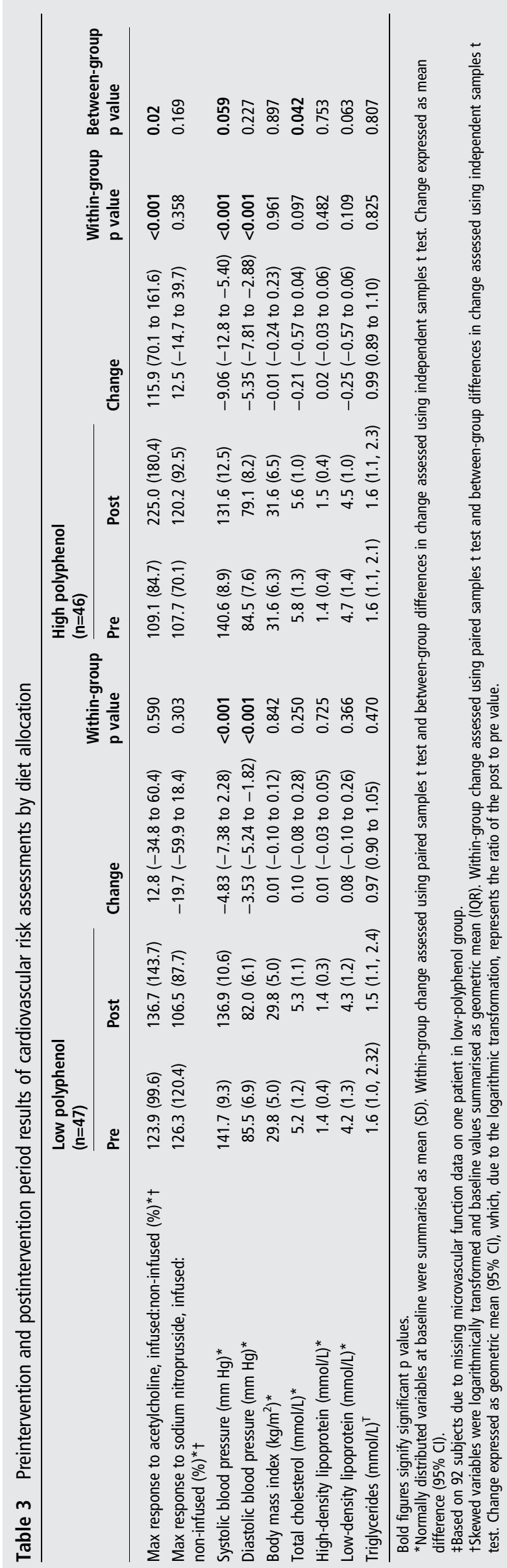


$\pm 9.3 \mathrm{~mm} \mathrm{Hg}$ pre vs $136.9 \pm 10.6 \mathrm{~mm} \mathrm{Hg}$ post, $\mathrm{p}<0.001)$ and high-polyphenol group $(140.6 \pm 8.9 \mathrm{~mm} \mathrm{Hg}$ pre vs 131.6 $\pm 12.5 \mathrm{~mm} \mathrm{Hg}$ post, $\mathrm{p}=0.001$ ) by 4.8 and $9.0 \mathrm{~mm} \mathrm{Hg}$, respectively.

There was a significant between-group difference in change in total cholesterol with the high-polyphenol diet showing an improvement $(0.2 \mathrm{mmol} / \mathrm{L}$ reduction) compared with an increase in concentration in the low-polyphenol diet $(0.1 \mathrm{mmol} / \mathrm{L}$ increase) $(p=0.042)$. There were no significant between-group differences in change in any of the remaining lipid parameters.

\section{DISCUSSION}

The PPhIT study aimed to extend a previous dietary intervention (FAVRIT) that had been shown to improve microvascular function in hypertensive subjects. This study develops those findings by showing that increasing polyphenol content with the addition of berries and dark chocolate potentially has additional benefits on microvascular function and CVD risk. The ideal combination of polyphenol-rich foods for cardiovascular health remains under debate. It was hypothesised that this diet would provide increased benefits to cardiovascular health and, importantly, given its palatability, be easily adopted by the general public.

The primary endpoint of the PPhIT study was between-group change in maximum FBF response to the endotheliumdependent vasodilator, ACh. Between-group comparison showed that those subjects who received a high-polyphenol diet had a significantly greater improvement in maximum \% response to $\mathrm{ACh}$, compared with the low-polyphenol group $(p=0.02)$. This suggests that increasing consumption of polyphenol-rich foods improves endothelium-dependent FBF response in hypertensive volunteers.

Therefore, the present findings indicate that increasing polyphenol intake, and specifically including berries, alongside consumption of a moderate portion of dark chocolate, could result in a significant improvement in endothelium-dependent responses. The available prognostic association data ${ }^{10}$ suggest that improving endothelium-dependent FBF with a diet rich in polyphenols could potentially modify CVD risk. An effect due to displacement of other foods from participants' diets cannot, however, be excluded.

There was a significant between-group change in reported F\&V intake. Given that self-reported data are prone to reporting bias, independent confirmation was provided by biomarkers, including assessment of plasma vitamin $\mathrm{C}$ and a panel of serum carotenoids. This indicated good compliance with the dietary intervention. The epicatechin content of the dark chocolate provided to participants was not measured during this study. However, previous studies have measured epicatechin levels in the brand of dark chocolate used in this intervention. Using these data, the amount of dark chocolate provided would have delivered a dose of $35.7 \mathrm{mg}$ epicatechin/day. ${ }^{23}$ Compliance with dark chocolate was demonstrated by a significant increase in evening meal to midnight urinary epicatechin levels detected on between-group testing. Urinary epicatechin use has been found to be superior to plasma epicatechin measurement as peak levels are detected $6-12 \mathrm{~h}$ postconsumption. ${ }^{24} 25$ The addition of dark chocolate to the regimen may have increased the palatability of the diet. Participant feedback showed a 90\% approval rating for the overall diet, indicating that it was well tolerated. ${ }^{26}$

There was a trend towards greater lowering in SBP within the high-polyphenol group compared with the low-polyphenol group (mean change: $-9.1 \pm 12.4 \mathrm{~mm} \mathrm{Hg}$ vs $-4.8 \pm 8.7 \mathrm{~mm} \mathrm{Hg}$ respectively, $\mathrm{p}=0.059$ ) on between-group analysis. Both SBP and diastolic BP decreased significantly on within-group analysis. However, the decrease in BP in both active and control groups may represent 'regression to the mean' ${ }^{27}$ a phenomenon that has been described in previous BP studies. ${ }^{2}$ Few polyphenol dietary intervention trials have assessed SBP. Previous calculations estimate that 115 participants would be required per group to detect a $5 \mathrm{~mm} \mathrm{Hg}$ change in SBP with $90 \%$ power; therefore, this study may have been underpowered to detect a difference in SBP between groups, and a type II error is possible. $^{2}$

Between-group testing demonstrated a significantly greater reduction in total cholesterol $(p=0.042)$ and a trend for greater
Figure 3 Dose-response curves of FBF ratio (infused:non-infused with error bars indicating standard error of mean) during saline and increasing concentrations of $\mathrm{ACh}$ for high-polyphenol and low-polyphenol diet preintervention and postintervention. Change in low-polyphenol group 12.8 (-34.8 to $60.4)$ versus change in high-polyphenol group 115.9 (70.1 to 161.6$)$ ( $p=0.02$ ). Based on 92 subjects due to missing microvascular function data on one patient in the low-polyphenol group. Ach, acetylcholine; FBF, forearm blood flow.

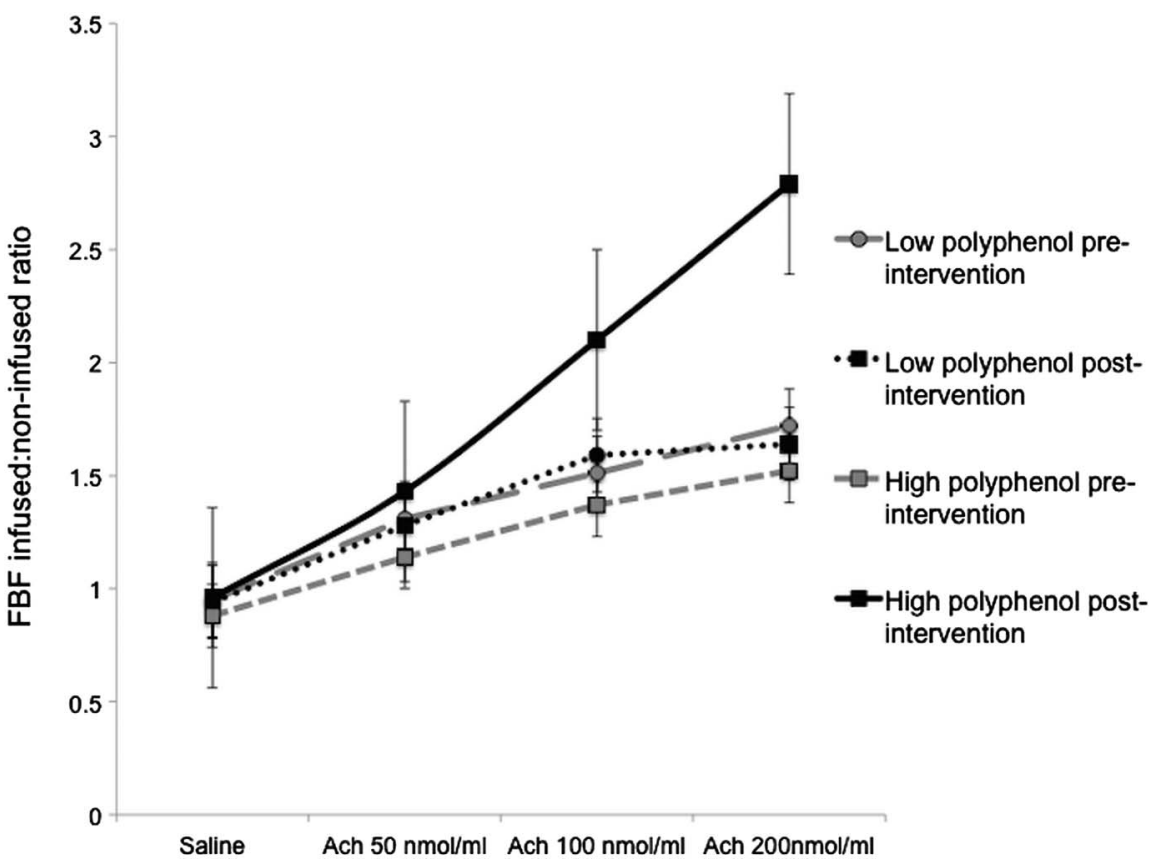


decrease in LDL ( $p=0.063$ ) in the high-polyphenol group compared with the low-polyphenol group. To put this into a clinical context, the change postintervention in LDL in high-polyphenol group in the PPhIT study equated to a $4.3 \%$ decrease in LDL concentrations, which, based on published data, would equate to a reduction in CVD mortality of approximately $4 \% .{ }^{28}$

In contrast to the PPhIT study, most polyphenol studies have used single food interventions. Combining different polyphenolrich foods may provide a cumulative increase in benefit due to the synergistic effect of several bioactive compounds. Potential mechanisms for the beneficial effects of polyphenols include their antioxidant and vasodilator functions, their ability to alter the expression of endothelial nitric oxide synthase and their ability to induce production of other endogenous vasodilators. However, many other cardiovascular benefits may exist, as described in recent reviews. ${ }^{29}{ }^{30}$ The participants in the PPhIT study were free-living and allowed to make their own choices of type of F\&V to be consumed. They also had hypertension and other cardiovascular risk factors. The results, therefore, are more relevant to 'real-life' than studies involving inpatient admission or supervised meals.

A concerted effort was made to keep other lifestyle variables constant during the study, reflected by static BMI and activity levels. However, in free-living individuals it is impossible to control for all variables in lifestyle. Due to budget and time constraints the PPhIT study was unable to use a factorial design to allow examination of the specific effect of berries and dark chocolate over and above increasing $\mathrm{F} \& \mathrm{~V}$ intake alone. As such this study cannot conclusively state whether polyphenols or other bioactive components within these foods, such as carotenoids or vitamin $\mathrm{C}$, working in isolation or synergistically, have led to the improvement in the primary endpoint. Future work could include comparison between low and high $F \& V$ versus high-polyphenol diets to definitively test the hypothesis that a

\section{Key messages}

\section{What is already known on this subject?}

Previous epidemiological and intervention study evidence suggests that increasing fruit and vegetable consumption improves cardiovascular disease risk. More specifically, observational evidence to date indicates that polyphenol-rich foods, in particular berries and dark chocolate, may influence cardiovascular disease risk. However, there are few polyphenol-specific dietary intervention studies of sufficiently robust design that assess the effect of polyphenol-rich foods on microvascular function.

\section{What might this study add?}

Our group conducted a randomised control trial and found that increasing intake of polyphenol-rich foods, in the form of fruit and vegetables (including berries) and dark chocolate, for 8 weeks resulted in a significant improvement in endothelium-dependent vasodilation in hypertensive participants.

\section{How might this impact on clinical practice?}

This study suggests that a well-tolerated polyphenol-rich diet through the simple addition of berries and dark chocolate could have a positive effect on microvascular function and cardiovascular risk. greater improvement in FBF responses to ACh can be achieved with specific inclusion of polyphenol-rich foods, compared with an F\&V-rich diet alone.

\section{CONCLUSIONS}

Increasing intake of polyphenol-rich foods, in the form of $\mathrm{F} \& \mathrm{~V}$, berries and dark chocolate, for 8 weeks resulted in a significant improvement in endothelium-dependent vasodilation in hypertensive participants. This study suggests that a well-tolerated polyphenol-rich diet could have a positive effect on microvascular function and cardiovascular risk.

Acknowledgements We acknowledge Professor Margaret Cupples and the Northern Ireland Clinical Research Network (Primary Care) for their assistance with participant recruitment, Dr Lesley Hamill for conducting the epicatechin analysis and Dr Sarah Gilchrist for performing vitamin C and carotenoid analysis. Also, we thank all of the participants in the study for their time, interest, cooperation and contribution to the research.

Contributors RLN was responsible for study design, conducting of trial, data collection, statistical plan and analysis, preparation of draft and revised manuscript. CR was responsible for conducting of trial and data collection, and preparation of draft and revised manuscript. DMcCall was responsible for study design and preparation of draft and revised manuscript. DMcCance was responsible for study design and preparation of draft and revised manuscript. ISY was responsible for study design and preparation of draft and revised manuscript. MCM was responsible for study design, statistical plan and analysis, and preparation of draft and revised manuscript. JW was responsible for study design, statistical plan and analysis, and preparation of draft and revised manuscript. PPM and MCM were responsible for study design and preparation of draft and revised manuscript and is the guarantor

Funding This study was funded by a Northern Ireland Health and Social Care Research and Development doctoral fellowship award (ref: EAT/4195/09) and Northern Ireland Chest Heart and Stroke scientific research grant (ref: 2010_17)

Competing interests None declared.

Ethics approval Office of Research Ethics Committee Northern Ireland (ref 10/ NIR03/39).

Provenance and peer review Not commissioned; externally peer reviewed.

\section{REFERENCES}

1 Appel LJ, Moore TJ, Obarzanek E, et al. A clinical trial of the effects of dietary patterns on blood pressure. DASH Collaborative Research Group. N Engl J Med 1997:336:1117-24.

2 McCall DO, McGartland CP, McKinley MC, et al. Dietary intake of fruits and vegetables improves microvascular function in hypertensive subjects in a dose-dependent manner. Circulation 2009;119:2153-60.

3 Cassidy A, Mukamal KJ, Liu L, et al. High anthocyanin intake is associated with a reduced risk of myocardial infarction in young and middle-aged women. Circulation 2013;127:188-96.

4 McCullough ML, Peterson JJ, Patel R, et al. Flavonoid intake and cardiovascular disease mortality in a prospective cohort of US adults. Am J Clin Nutr 2012:95:454-64.

5 Buijsse B, Feskens EJ, Kok FJ, et al. Cocoa intake, blood pressure and cardiovascular mortality. The Zutphen Elderly Study. Arch Intern Med 2006;166:411-17

6 Buijsse B, Weikert C, Drogan D, et al. Chocolate consumption in relation to blood pressure and risk of cardiovascular disease in German adults. Eur Heart $J$ 2010;31:1616-23.

7 Janszky I, Mukamal KJ, Ljung R, et al. Chocolate consumption and mortality following a first acute myocardial infarction: the Stockholm Heart Epidemiology Program. J Intern Med 2009;266:248-57.

8 Panza JA, Quyyumi AA, Brush JE, et al. Abnormal endothelium-dependent vascular relaxation in patients with essential hypertension. N Engl J Med 1990;323:22-7.

9 Linder L, Kiowski W, Buhler FR, et al. Indirect evidence for release of endothelium-derived relaxing factor in human forearm circulation in vivo. Circulation 1990;81:1762-7

10 Perticone F, Ceravolo R, Pujia A, et al. Prognostic significance of endothelial dysfunction in hypertensive patients. Circulation 2001;104:191-6.

11 Fichtlscherer S, Breuer S, Zeiher AM. Prognostic value of systemic endothelial dysfunction in patients with acute coronary syndromes: further evidence for the existence of the "vulnerable" patient. Circulation 2004;110:1926-32.

12 Taddei $S$, Virdis A, Mattei $P$, et al. Aging and endothelial function in normotensive subjects and patients with essential hypertension. Circulation 1995:91:1981-7.

$13 \mathrm{ESH} / \mathrm{ESC}$. $2013 \mathrm{ESH} / \mathrm{ESC}$ guidelines for the management of arterial hypertension. The Task Force for the management of arterial hypertension of the European Society 
of Hypertension (ESH) and of the European Society of Cardiology (ESC). European Heart Journal 2013:34:2159-219.

14 Eckel RH, Jakicic JM, Ard JD, et al. 2013 AHA/ACC Guideline on lifestyle management to reduce cardiovascular risk: a report of the American College of Cardiology/American Heart Association Task Force on Practice Guidelines. Circulation 2014;129(Suppl 2):S76-99.

15 Williams B, Poulter NR, Brown MJ, et al. British Hypertension Society guidelines for hypertension management (BHS-IV): summary. BMJ 2004:328:634-40.

16 Kroke A, Klipstein-Grobusch K, Voss S, et al. Validation of a self-administered food-frequency questionnaire administered in the European Prospective Investigation into Cancer and Nutrition (EPIC) Study: comparison of energy, protein, and macronutrient intakes estimated with the doubly labeled water, urinary nitrogen, and repeated 24-h dietary recall methods. Am J Clin Nutr 1999;70:439-47.

17 Spencer JP, Abd El Mohsen MM, Minihane AM, et al. Biomarkers of the intake of dietary polyphenols: strengths, limitations and application in nutrition research. $\mathrm{Br} J$ Nutr 2008;99:12-22.

18 Wilkinson IB, Webb DJ. Venous occlusion plethysmography in cardiovascular research: methodology and clinical applications. Br I Clin Pharmacol 2001:38:1461-6.

19 Vuilleumier JP, Keck E. Fluorometric assay of vitamin C in biological materials using a centrifugal analyser with fluorescence attachment. J Micronutrient Anal 1989;5:25-34.

20 Craft NE. Carotenoid reversed-phase high-performance liquid chromatography methods: reference compendium. Meth Enzymol 1992;213:185-205.

21 Friedewald WT, Levy RI, Fredrickson DS. Estimation of the concentration of low density cholesterol in plasma without use of the preparative ultracentrifuge. Clin Chem 1972;18:499-502.
22 Pearson TA, Mensah GA, Alexander RW, et al. Markers of inflammation and cardiovascular disease: application to clinical and public health practice: a statement for healthcare professionals from the Centers for Disease Control and Prevention and the American Heart Association. Circulation 2003:107:499-511.

23 Gottumukkala RVSS, Nadimpalli N, Sukala K, et al. Determination of Catechin and Epicatechin content in chocolates by high-performance liquid chromatography. Int Scholar Res Notes 2014;2014:1-5.

24 Roura E, Almajano MP, Bilbao MLM, et al. Human urine: epicatechin metabolites and antioxidant activity after cocoa beverage intake. Free Radic Res 2007:41:943-9.

25 Baba S, Osakabe N, Kato Y, et al. Continuous intake of polyphenolic compounds containing cocoa powder reduces LDL oxidative susceptibility and has beneficial effects on plasma HDL-cholesterol concentrations in humans. Am J Clin Nutr 2007;85:709-17

26 Rooney C. Polyphenol intake, Dietary Patterns and Psychological Analysis. 2013 Unpublished PhD thesis. Queen's University Belfast.

27 Tu YK, Gilthorpe MS. Revisiting the relation between change and initial value: a review and evaluation. Stat Med 2007;26:443-57.

28 Grundy SM, Cleeman Jl, Merz CN, et al. Implications of recent clinical trials for the National Cholesterol Education Program Adult Treatment Panel II Guidelines. J Am Coll Cardiol 2004;44:720-32.

29 Nijveldt RJ, van Nood E, van Hoorn DE, et al. Flavonoids: a review of probable mechanisms of action and potential applications. Am J Clin Nutr 2001;74:418-25

30 Andújar I, Recio MC, Giner RM, et al. Cocoa polyphenols and their potential benefits for human health. Oxid Med Cell Longev 2012;2012:1-23. 